There is little doubt but that sprains and injuries to the ankle may have associated at times a damaged epiphyscal cartilage, a recognition of which would lead to a more careful prognosis.

'These epiphyseal injuries are important because the joint surface is involved in the damaged area. Any interference with an articular surface may lead to impairment of motion in that joint.

\section{ETinical Đepartment.}

\section{REPOR'T OW A CANE OH MYOTONIA.}

BS EDWIN A. DOWN, M.1), "IAlt'JOUL, CONN.

Is considering the symptoms, nature and course of myospasms generally, and those of 'Thomson's syndrome particularly, a doubt may insinuate itself in the progress of one's deliberations respecting the validity of the claim held by some that every case of genuine myotonia must bear the trademark " $a b$ ovo," notwithstanding the existence of identical symptoms in cases not possessing this prenatal qualification. While it is assumed that only a waning minority stills clings to the hereditary element as essential to a correct diagnosis, it was decmed fitting that the following brief history of a case should be placed on record as confirming the view of the existence of cases manifesting the cardinal symptoms of myotonia, in which neither hereditary nor congenital influences have any part, and that such cases should be entitled to full fellowship in the fraternity of myotonic states.

The history of the case as here given is a compound of the statements of the patient and the family physician, and includes the following items.

Male; fifty-six years of age; occupation, market gardening. Ilas always lived an out-of-door life and is a good representative of the sturdy and sinewy type of New lingland farmer.

Is married and his family history is excellent, hereditary disorders of any sort being positively excluded, and the existence of any chronic disorder cither neurotic or otherwise, in the family lincage being absolutely negative so far as the knowledge of the patient cxtends.

Habits regular regarding the use of alcoholic drinks and associated excesses. Is considered a model citizen.

$\therefore$ Assigned cause, overwork; duration of attack, one ycar; onset of attack, subacute.

The patient makes the stutement that he was thrown from a wagon twenty years ago, and though not losing consciousness, was believed to have suffered a slight cerebral concussion. He was unable to state anything concerning the nature of the symptoms munifested at the time which would justify the diagllosis, and the physician who attended him is not now living; hence this feature of the history is a matter for conjecture, though it must be borne in mind that the injury has in no way interfered with the discharge of his regular duties since the mishap, and there has existed no sensation or other feature which might serve as a reminder that the accident had ever occurred.

'The present symptoms have existed for a year or more and consist of a rigidity of the muscles upon attempts at movement, more marked in the lower limbs, the condition becoming intensified after periods of rest. A typical diumal experience is portrayed in the following train of symptoms.

Conditions are at their most aggravated stage in the morning immediately after waking, if any attempt at movement is made. Rising from his bed is quite it process if unaided, and is accomplished only after mally awkward and vexatious attempts.

Ilis first procedure is to grasp the knees firmly with the hands, and by persistent traction draw the trunk into the upright position. This being attained, he employs his buttocks as a pirotal center and turns his feet toward the side of the bed, where he remains a few minutes in a rigid condition before venturing to stand upon his feet. For this latter purpose he employs a cane or other aid, and when he is finally in an upright posture he is utterly unable to move on aceount of the rigidity of the limbs which "feel like sticks of wood" if he attempts to use them. Interpolating one of his forceful utterances, "Doctor, I could not move if my house was on fire," we gain a definite irlea of the condition of things from his viewpoint. He requires assistance in dressing and undressing, though more frequently the former, for toward evening, after exertion, the contractions are decidedly much less marked and a near approach to the normal attained.

The rigidity was first apparent in the lower limbs and confined itself to this location for several months before involving the upper extremities. During this interval he was able to milk his accustomed number of cows, though he experienced great difficulty in rising from the sitting posture, and in using his limbs in walking after rising, until af ter the lapse of a minute or more on account of the extreme muscular contraction.

The tenacity with which he adhered to his work is well illustrated in an account given by one of his neighbors. It appears that this neighbor was passing the garden in which our patient was engaged in weeding some veretables. The neighbor noticed that the patient did not rise from the furrow in his progress from one plant to another, but dragged himself along with his hands, while his feet trailed after him in a manner which, to the observer, suggested paralysis. Inquiring as to the cause of this unconventional method of locomotion, it was ascertained that the paticnt's legs became so rigid, after successive attempts necessitated by frequent changes of location, as to render them temporarily useless, and he preferred this unusual mode of progress to the delay resulting from rising each time he wished to alter his position, and losing several minutes before the spasm was sufficiently relieved to allow him to procecd. No material change was noticed for a period of about eight months, when the upper extrenities became involved, and only sporadic attempts at any form of occupation were possible. Full arm movements were as difficult as those of the hands and fingers, and during this stage of the disorder the ability to raise the hand above the shoulder was completely lost on account of the spasms.

On the sensory side vasomotor symptoms in the form of cold feet and limbs were present, added to which was a very annoying feature characterized by a sensation of intense cold in both ears. This algid condition caused more concern than the muscular rigidity, and during the warmest days in August the hot-water bag was frequently appealed to in order to mitigate the suffering from this source. This symptom was not present early in the disorder and persisted after the subsidence of the muscular contractions. I 
do not recull seeing this thermic perversion noted in the histories of other eases, and speculation as to its value in the makeup of the disorder we are considering can be indulged in with propriety. We may regard it as a simple coincidence from one point of view, or as an indication of the involvement of the thermic centers of the posterior root processes, or both.

some "soreness" was complained of at the time of the maximum contraction of the muscles, and the middle thited of the right arm was the most sensitive area. There was no pain in the ordinary sense at any time.

Sometimes unpleasant sensations were experienced while endeavoring to place his lower limbs in a comcomfortable position in bel. His legs felt as if they "did not fit" in any position he chose to place them. His remedy was to get out of the bed as best he could and move about the room for a few minutes, after which exercise he was able to lie down with some degree of comfort.

Occasionally there was a slight tremor of the hands (non intention) which soon disappeared on exercise. Patellar reflexes symmetrically increased; other reflexes normal.

Gait was slow and shufling when walking was first attempted, but after a few minutes' exercise there was nothing to attract attention in this direction. Station nojmal. No involvement of the cranial nerves. 'The treatment was directed toward the improvement of the general health and an antispasinodic was included.

There was a limited hypertrophy of the calf muscles, and the mechanical excitation of these as well ats the chicf groups of muscles involved in the spasmodic phenomena was noticeably increased; this held good for electrical stimulation also, whereas the motor nerve response was unaltered.

Marked improvement followed after a few months from the time of the first examination, or one year and a half from the onset of the disorder, when the symptoms had so far subsided as to admit of his resuming light employment in accustomed spheres.

Attacks recurring at irregular intervals but with diminished severity have characterized the condition of things up to the present writing, but a return to an absolutely normal state has thus far not materialized.

The shadow of a resemblance to an occupation neurosis, and the possible existence of an organic cord affection, were not lost sight of in forming an opinion as to the nature of the disorder, but in view of the progress of the case, as well as its capital fentures, the diagnosis of a myotonic condition would appear to be fully justified.

\section{Agedical Brogregs.}

\section{P'ROGRESS IN DERNATOLOGY.}

BY HallVEY 1. TUWIA, M.D., mok'TON.

THE SERUM DIAGNOSIS OF SYPHIJIS.

So long as clinical observation remained the only method by which the diagnosis of syphilis could be made there were many cases which we were obliged to leave in doubt. When, however, the spirochete pallida and the possibility of transmitting syphilis to animals were discovered, the means of diagnosis was at once so enriched that we were now able to render the diangusis certain in many of these formerly doubtful cases. In 1906 Wassermann proposed still another method as an aid to the diagnosis of syphilis, which is referred to in the literature as the IVassermann reaction, or the method of serodiagnosis, or the serum reaction, or the method of the

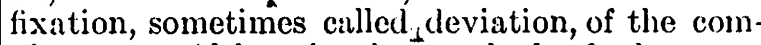
plement. Although the method of the serodiagnosis of syphilis is still on trial, so much has already been reported which at least suggests its possible importance that it warrants our consideration. If the claims of its adrocates are substantiated by its further study this method will enlarge our diagnostic power's still more so that many cases which still remain beyond our present neans will be brought within our certain knowledge. J3efore we can judge fairly, however, of the claims made for the method of serodiagnosis in syphilis, we must have not only a clear understanding of the complicated theory upon which the method is founded but also of the characteristics of the various reagents.

In 1901 Bordet and Gengou ${ }^{1}$ published their method for the diagnosis of certain bacterial diseases, notaloly typhoid, by means of a serum reaction. It was already known that the injection of certain bacterial emulsions or vaccines made from dead or living bacteria would render the organism immune to that bacterium. Such vaccines, therefore, represented the actual substance of the microbe and were termed antigen. It had been also discovered that injections of the antigen not only conferred immunity upon the organism, but at the same time stimulated it to the production of certain defensive substances in its serum which were called antibodies. 'These antibodies were characterized by a specific or selective action in that they would react only to the particular antigen (bacteria) to which they owed their existence ${ }^{15}$; when such "immune sera," obtained from an animal which had previously bcen treated by a series of injections of a bacterial emulsion (antigen), were mixed with the appropriate antigens (emulsion), bacteriolysis occurred, that is, the bacteria (antigen) were immobilized, transformed into granules and even dissolved. ${ }^{15}$

Antibodics. - Investigation of the antibodies showed that they were composed of two substances of widely divergent characteristics which have been termed the amboceptor and the complement. Moreover, it was learned that unless both amboceptor and complement were present in the serum aduled to the antigen, there was no hacteriolysis. As will be seen later, this fact, that neither amboceptor or complement, when alone, can produce the reaction, was of great importance in the application of the theory to the actual test.

Bacleriolysis. - The explanation of bacteriolysis given by Ehrlich and Morgenroth ${ }^{15}$ is that the bacteria (antigen) are impregnated by the specific amboceptor after the manner of a coloring matter and are thereby rendered susceptible to the bacteriolytic power of the complement. At the 